\title{
What Motivates Costless Altruism? Evidence from Laboratory Experiments
}

\author{
Zhi Fan', ${ }^{1,2}$ Keqiang Li1, Ya Zhou ${ }^{*}$ \\ ${ }^{1}$ School of Systems Science, Beijing Normal University, Beijing, China \\ ${ }^{2}$ Department of Basic Courses, Beijing Union University, Beijing, China \\ Email: ${ }^{\star}$ zhouya@bnu.edu.cn
}

How to cite this paper: Fan, Z., Li, K. Q., \& Zhou, Y. (2020). What Motivates Costless Altruism? Evidence from Laboratory Experiments. Theoretical Economics Letters, 10, 273-280.

https://doi.org/10.4236/tel.2020.102017

Received: February 5, 2020

Accepted: March 29, 2020

Published: April 1, 2020

Copyright $\odot 2020$ by author(s) and Scientific Research Publishing Inc. This work is licensed under the Creative Commons Attribution International License (CC BY 4.0).

http://creativecommons.org/licenses/by/4.0/

\begin{abstract}
Costless altruistic behaviors are special altruistic behaviors that benefit others at no own cost. While in literature, the motivations of typical altruistic behaviors that generally involve own cost have been studied intensively, it is not clear yet, on the flip side, what motivations drive costless altruistic behaviors. In this paper, we examine how often costless altruistic behaviors happen and, if not always, the potential determinants of costless altruistic behaviors. Specifically, we conduct a series of human-computer experiments of repeated emotion game, separating the impacts of emotion and payoff on the occurrence of costless altruistic behaviors. We find that costless altruistic behaviors do not always happen, and the considerations regarding emotion (e.g., reciprocity) and self-payoff are two important determinants. Additionally, we find that rewarding altruistic behaviors and punishing unaltruistic behaviors lead to more costless altruistic behaviors, thus, can potentially promote the overall social welfare.
\end{abstract}

\section{Keywords}

Costless Altruistic Behaviors, Self-Interest, Reciprocity, Reward, Punishment

\section{Introduction}

Altruism refers to willingness and behaviors to benefit others. The causes of altruistic behavior have been studied intensively in many fields, including psychology, economics and so on. Literature shows that to behave altruistically people can be motivated by pure altruism (Charness \& Rabin, 2002), warm glow (Andreoni, 1989), reciprocity (Hein et al., 2016), inequality aversion (Blanco et al., 2011), or even self-interest: a self-interested kid may act altruistically, i.e., maximizes utility of the entire family while maximizes his/her own utility, if the parents are altruistic (Becker, 1974). 
Altruistic behaviors do not have to be at one's own cost. For example, in a generosity game (e.g., Güth, 2010) where the proposer chooses the total payoff with his/her own payoff fixed, he/she can benefit the responder without any cost, by choosing a larger total payoff. In practice, such costless altruistic behaviors are more likely to occur than those with cost (Güth, et al. 2012; Zhao et al., 2016). However, it is not clear if costless altruistic behaviors always happen, e.g., when people have spiteful preference (Fehr et al., 2008b). Moreover, besides the consideration of cost, whether there are other factors that motivate costless altruistic behaviors remains unclear. The existing research mainly focuses on the causes of altruism with cost, but little is known about the causes of costless altruism. For instance, in the two-person generosity game, the reasons for the proposer's altruistic proposal with the larger total payoff could be pure altruism, egocentric altruism and team reasoning, but no distinction has been made among these causes (Güth et al., 2012).

In the setting of repeated interactions there are two well-known strategies as potential motivators for general altruistic behaviors-all-cooperation strategy and "tit for tat" strategy. People who choose all-cooperation strategy will always cooperate (thus, benefit others) regardless how others behave. All-cooperation strategy could make others who want reciprocity also behave altruistically, i.e., cooperate. However, it is known that all-cooperation strategy, which is essentially an unresponsive strategy, does not effectively promote the cooperation of others because there is no punishment for choosing non-cooperation (Miller, 1985). On the flip side, people who choose "tit for tat" strategy will cooperate only if others also cooperate. "Tit for tat" strategy can promote cooperation more effectively because now people know that they will trigger others' non-cooperation (thus, get punished) if they choose non-cooperation (Axelrod, 1984; Sandoval et al., 2016). Compared to the all-cooperation strategy, the "tit for tat" strategy is more likely to lead to long-term cooperation by punishing defect and rewarding cooperation. In this paper, we examine if all-cooperation and "tit for tat" strategies work the same way affecting costless altruistic behaviors, as well as the emotional motivations regarding, e.g., reciprocity, and self-interest behind the two strategies, in a setting of repeated interactions.

Specifically, we conduct two sets of experiments about repeated emotion games. We find that costless altruistic behaviors do not always happen. Emotional determinants such as reciprocity and self-interest are both important motivators for costless altruistic behaviors. Rewarding altruistic behaviors and punishing unaltruistic behaviors makes costless altruistic behaviors more likely to occur.

\section{Emotion Game}

Our experiment is based on the following game, which is defined as an emotion game. Specifically, the payoff matrix looks like the following: 


\begin{tabular}{llcc}
\hline & & \multicolumn{2}{c}{ Player 2 } \\
\cline { 3 - 4 } & & 1 & 2 \\
\hline \multirow{2}{*}{ Player 1 } & 1 & 1,1 & 2,1 \\
& 2 & 1,2 & 2,2 \\
\hline
\end{tabular}

The game is a symmetric game, with each player's payoff solely determined by the other's choice. For example, given player 1's choice, say option 1, player 2 would get the same payoff of 1 no matter what he/she chooses. However, player 2 can behave altruistically at no cost by choosing option 2: while his/her payoff still totally depends on player 1's choice, player 1 can get the higher payoff of 2 for sure.

One important feature of the emotion game above is that the determinants of player's choice other than payoff, e.g., emotional considerations based on reciprocity, can be separately identified. For example, in a one-shot static emotion game, since a player's payoff does not depend on his/her own choice, a rational player who cares about own payoff only will choose randomly between two options, and a population of such players will choose either options in $50 \%$ of the observations (Fehr, et al. 2008a). Similarly, in repeated emotion games with one player's (say, player 1's) choices fixed (e.g. always choosing the same option or randomly choosing an option according to a fixed probability), the other player (say, player 2) has the same own expected payoff regardless of what he/she chooses. Therefore, if player 2 is rational, caring about own payoff only, he/she will also choose randomly between two options and a population of player 2 will choose either option with 50\% frequency. But if player 2 has considerations other than own payoff, we may observe different population outcomes. In the repeated emotion games above, player 2 may always choose the same fixed option as player 1 , for example, if he/she wants reciprocity. Therefore, by the repeated emotion games with one player's choices fixed, we can examine whether emotion affects choices (thus, leads to costless altruistic behaviors). Additionally, we can examine the impacts of own payoff on choices by allowing player 1 to act responsively, e.g., making choices according to the strategy of "tit for tat", because now player 2 can increase own payoff by strategically affecting player 1's choices via his/her own choices. Finally, combining the results from the two scenarios with different decision rules of player 1, we are able to compare the effects of considerations based on emotion and own payoff on the likelihood of costless altruistic behaviors.

\section{Experimental Design}

Our experiment includes two treatments: emotion games with complete altruism (CAEG) and emotion games with "tit for tat" strategy (CTFT). For the purpose to fix one player's behaviors, in all our games a human player was matched with a computer, whose choice was predetermined according to a specific rule. In 
both treatments, a human player played emotion games with his/her computer opponent (partner, unchanged once paired) for 100 periods. In CAEG, the computer always chose option 2 in the first 50 periods and then switched to option 1 in the last 50 periods. The human player knew that the computer would make choices according to a fixed rule, regardless of his/her choices, but he/she did not know what the rule was. In CTFT, the computer made choices according to a "tit for tat" strategy, by starting with option 2 in the first period and then duplicating the human player's choice from the previous period. Again, the human player knew that the computer's choice would depend on his/her previous choices, but didn't know the rule. In both treatments, the human player and the computer made decisions at the same time. When making decisions, they didn't know each other's choices. At the end of each period, the human player was informed of both players' decisions and payoffs in the current period.

In our experiments (both treatments) the human players' behaviors should not be mainly driven by pure altruism, because they knew that their opponents, the computers, did not get any real payoff. In CAEG, since the human players' payoffs were given once the computers' choice rules were set up, the human players' choices should not be driven by self-interest either. Therefore, we are able to test if costless altruistic behaviors can be driven by emotional considerations, e.g., reciprocity, by testing if in CAEG the sample frequency for all the human players to choose option 2 was significantly higher in the first 50 periods (when the computers always chose option 2) than the last 50 periods (when the computers always chose option 1). We should also note that the comparison could also help exclude certain other motivators, such as efficiency concerns and maximin preferences, which are argued to be potential confounders for inequality aversion (Engelmann \& Strobel, 2004; Engelmann, 2012). In CTFT, since the human players could be rewarded (or punished) if they chose option 2 (or 1) in the previous period, self-interest could be one of the motives for their choices. So additionally, we can test whether costless altruistic behaviors are more likely when such behaviors and the opposite unaltruistic behaviors are rewarded and punished respectively, by testing if the sample frequencies for all the human players to choose option 2 differ between CAEG (the first 50 periods) and CTFT.

Our experiment was conducted for 12 sessions in Beijing Normal University, China, in September 2016. The experiment was programmed using the $\mathrm{z}$-Tree software (Fischbacher, 2007). All the human players were college students recruited from BBS (Bulletin Board System) of Beijing Normal University. Each human player was allowed to participate only once, in either of the two treatments. Each human player's accumulated nominal payoffs of 100 periods were converted to a real payoff according to the following equation: 5 points nominal payoff $=1 \mathrm{CNY}$ (Chinese currency). The experiment lasted for approximately 40 minutes. When the experiment concluded after 100 periods, each human player answered a questionnaire for demographic information such as gender and major (see Appendix Table A1 for demographic statistics). All human players got a 
show-up fee (10 CNY) in addition to the real experimental payoffs. The average payoff of the human players was $40 \mathrm{CNY}$ (5.65 USD) in CAEG and $48 \mathrm{CNY}$ (6.78 USD) in CTFT.

\section{Results}

The frequency for the human players to choose option 2 in all periods of CAEG and CTFT is shown in Figure 1 and Figure 2, respectively. We find that costless altruistic behaviors do not always happen. In our experiments in either treatment, the frequency for the human players to choose option 2 was not one (0.52 in CAEG and 0.89 in CTFT). Moreover, to what extent the human players behave altruistically depends on the computers' choices. In the first (last) 50 periods of CAEG, the frequency for the human players to choose option 2 was 0.76 (0.28), which was substantially higher (lower) than 0.50 . Those results indicate

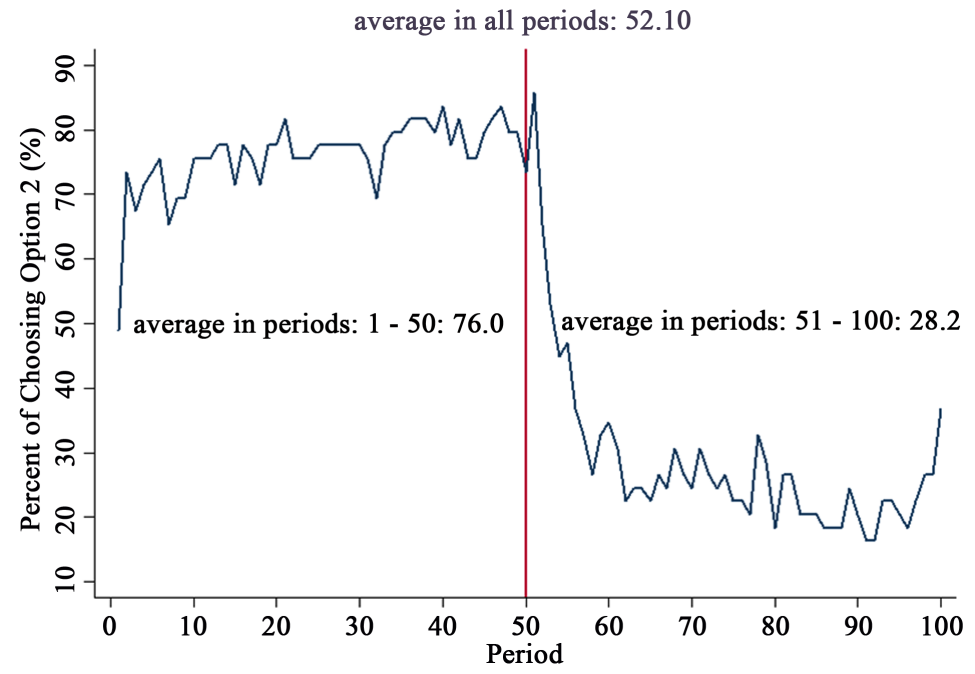

Figure 1. Percent of human players choosing option 2, CAEG.

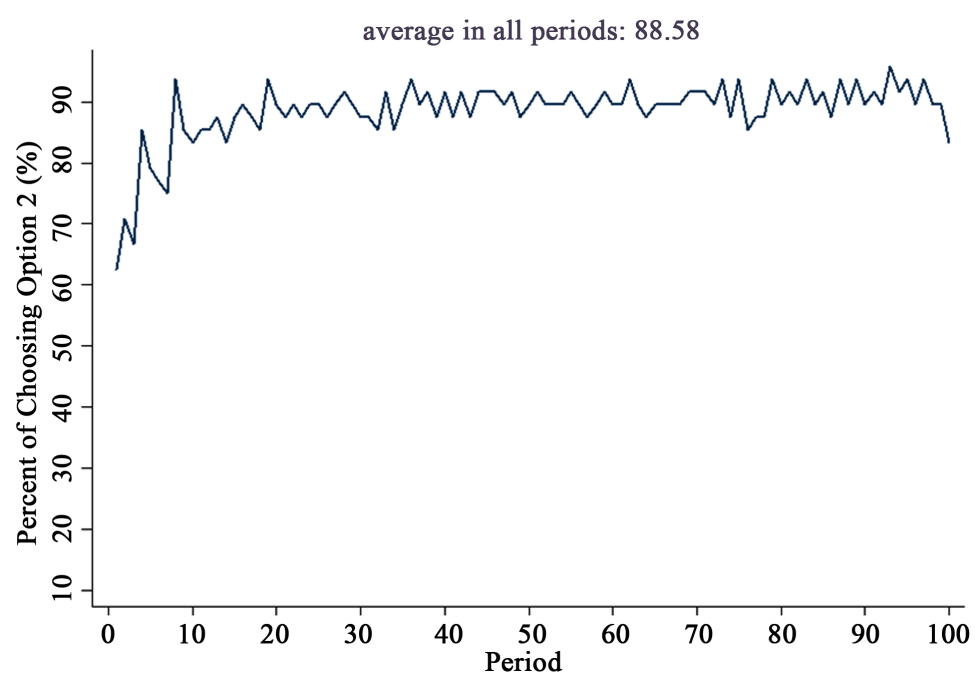

Figure 2. Percent of human players choosing option 2, CTFT. 
that costless altruistic behaviors could be driven by determinates other than payoff, such as emotional considerations about reciprocity: the human players were more likely to behave altruistically at no cost when the opponent computers were set to be altruistic ${ }^{1}$. The frequency for the human players to choose option 2 in CTFT was 0.89 , which was also higher than 0.50, indicating that concerns about own payoff also play roles in determining costless altruistic behaviors: with the opponent computers playing "tit for tat" strategy, the human players would behave altruistically to increase their own payoffs, by triggering the computers' altruistic behaviors. Finally, in additional to higher average, the distribution of the frequency for human players to choose 2 in CTFT was significantly different from that in the first 50 periods of $\mathrm{CAEG}^{2}$. Compared with the scenario of emotional consideration when the computers always behave altruistically (e.g., periods 1 - 50 of CAEG), costless altruistic behaviors of human players were more likely to occur in the scenario of self-interest when such behaviors would be rewarded in terms of higher own payoffs (e.g., CTFT ${ }^{3}$ ).

\section{Conclusion}

This study explores whether costless altruistic behaviors can always happen, and if not, what the potential determinants are, by specifically investigating different effects of the opponent's (un)responsive strategy on individual costless altruism in a series of experiments. We found that costless altruistic behaviors do not always happen. Both emotional considerations and self-interest have the potential to motivate costless altruistic behaviors. Compared with random response, in the scenario when the opponents always behave altruistically, people are more likely to respond altruistically as well at no cost, based on the emotional consideration regarding, e.g., reciprocity. In the scenario when the opponents act responsively with rules of reward and punishment, people also choose costless altruism at a higher possibility than pure randomness, based on the concerns regarding own payoff. Although neither emotional and self-interest determinants are able to make people always behave altruistically, the comparison between the two scenarios indicates that strategies with reward and punishment rules regarding altruistic behaviors can promote costless altruism better than unresponsive strategies of being altruistic forever. For increasing overall welfare by promoting costless altruistic behaviors, it seems a better idea to evaluate and respond to (e.g., reward or punish) others' behaviors in time rather than to tolerate undesirable behaviors all the time.

${ }^{1}$ We should note that the substantial difference in the frequency for the human players to choose option 2 between the first 50 and last 50 periods of CAEG also indicates that considerations regarding efficiency does not play an important role, as otherwise human player should stick to option 2 after the switch, which still maximized the total payoff of the two players.

${ }^{2}$ The Kolmogorov-Smirnov (K-S) nonparametric test, $\mathrm{KS}=1.489, \mathrm{p}=0.024$.

${ }^{3}$ We compare the results from 100 periods of CTFT to those from only 50 periods (the first 50) of CAEG. To make sure that our results are not driven by such difference in number of periods, as a robustness check we calculate the frequency for the human players to choose option 2 in CTFT using the first 50 periods, and obtain a very similar number $(86.8 \%)$. Our results are robust to whether we use the total of 100 periods or the first 50 periods of CTFT. 


\section{Conflicts of Interest}

The authors declare no conflicts of interest regarding the publication of this paper.

\section{References}

Andreoni, J. (1989). Giving with Impure Altruism: Applications to Charity and Ricardian Equivalence. Journal of Political Economy, 97, 1447-1458. https://doi.org/10.1086/261662

Axelrod, R. M. (1984). The Evolution of Cooperation. New York: Basic Books.

Becker, G. (1974). A Theory of Social Interactions. Journal of Political Economy, 82, 1063-1093. https://doi.org/10.1086/260265

Blanco, M., Engelmann, D., \& Normann, H. T. (2011). A Within-Subject Analysis of Other-Regarding Preferences. Games and Economic Behavior, 72, 321-338. https://doi.org/10.1016/j.geb.2010.09.008

Charness, G., \& Rabin, M. (2002). Understanding Social Preferences with Simple Tests. The Quarterly Journal of Economics, 117, 817-869. https://doi.org/10.1162/003355302760193904

Engelmann, D. (2012). How Not to Extend Models of Inequality Aversion. Journal of Economic Behavior and Organization, 81, 599-605. https://doi.org/10.1016/j.jebo.2011.08.007

Engelmann, D., \& Strobel, M. (2004). Inequality Aversion, Efficiency, and Maximin Preferences in Simple Distribution Experiments. American Economic Review, 94, 857-869. https://doi.org/10.1257/0002828042002741

Fehr, E., Bernhard, H., \& Rockenbach, B. (2008a). Egalitarianism in Young Children. Nature, 454, 1079-1083. https://doi.org/10.1038/nature07155

Fehr, E., Hoff, K., \& Kshetramade, M. (2008b). Spite and Development. American Economic Review, 98, 494-499. https://doi.org/10.1257/aer.98.2.494

Fischbacher, U. (2007). z-Tree: Zurich Toolbox for Ready-Made Economic Experiments. Experimental Economics, 10, 171-178. https://doi.org/10.1007/s10683-006-9159-4

Güth, W., Levati, M. V., \& Ploner, M. (2012). An Experimental Study of the Generosity Game. Theory and Decision, 72, 51-63. https://doi.org/10.1007/s11238-011-9253-8

Güth, W. (2010). The Generosity Game and Calibration of Inequity Aversion. Journal of Socio-Economics, 39, 155-157. https://doi.org/10.1016/j.socec.2009.10.012

Hein, G., Morishima, Y., Leiberg, S., Sul, S., \& Fehr, E. (2016). The Brains Functional Network Architecture Reveals Human Motives. Science, 351, 1074-1078. https://doi.org/10.1126/science.aac7992

Miller, N. R. (1985). Nice Strategies Finish First: A Review of the Evolution of Cooperation. Politics and the Life Sciences, 4, 86-91. https://doi.org/10.1017/S0730938400020852

Sandoval, E. B., Brandstetter, J., Obaid, M. et al. (2016). Reciprocity in Human-Robot Interaction: A Quantitative Approach through the Prisoner's Dilemma and the Ultimatum Game. International Journal of Social Robotics, 8, 303-317. https://doi.org/10.1007/s12369-015-0323-x

Zhao, K., Ferguson, E., \& Smillie, L. D. (2016). Prosocial Personality Traits Differentially Predict Egalitarianism, Generosity, and Reciprocity in Economic Games. Frontiers in Psychology, 7, 1137. https://doi.org/10.3389/fpsyg.2016.01137 
Z. Fan et al.

\section{Appendix}

Table A1. Gender and major of players by experimental treatments.

\begin{tabular}{lccc}
\hline & & CAEG & CTFT \\
\hline \multirow{2}{*}{ Gender } & Male & $14.3 \%$ & $18.8 \%$ \\
& Female & $85.7 \%$ & $81.2 \%$ \\
Major & Science & $55.1 \%$ & $41.7 \%$ \\
& Social & $32.7 \%$ & $27.1 \%$ \\
& Humanities & $12.2 \%$ & $31.2 \%$ \\
& Total number & 49 & 48 \\
\hline
\end{tabular}

